\title{
Inflammation- and lipid metabolism-related gene network expression in visceral and subcutaneous adipose depots of Holstein cows ${ }^{1}$
}

\author{
P. Ji, J. K. Drackley, ${ }^{2}$ M. J. Khan, and J. J. Loor ${ }^{2}$ \\ Department of Animal Sciences and Division of Nutritional Sciences, University of Illinois, Urbana 61801
}

\begin{abstract}
This experiment was conducted to determine the effects of energy overfeeding on gene expression in mesenteric (MAT), omental (OAT), and subcutaneous (SAT) adipose tissue (AT) from nonpregnant and nonlactating Holstein cows. Eighteen cows were randomly assigned to either a controlled energy [LE, net energy for lactation $\left(\mathrm{NE}_{\mathrm{L}}\right)=1.35 \mathrm{Mcal} / \mathrm{kg}$ of dry matter $\left.(\mathrm{DM})\right]$ or moderate energy-overfed group $\left(\mathrm{HE}, \mathrm{NE}_{\mathrm{L}}=1.62 \mathrm{Mcal} /\right.$ $\mathrm{kg}$ of $\mathrm{DM}$ ) for $8 \mathrm{wk}$. Cows were then euthanized and subsamples of MAT, OAT, and SAT were harvested for transcript profiling via quantitative PCR of 34 genes involved in lipogenesis, triacylglycerol (TAG) synthesis, lactate signaling, hepatokine signaling, lipolysis, transcription regulation, and inflammation. The interaction of dietary energy and adipose depot was not significant for any gene analyzed except $L P L$, which indicated a consistent response to diet. Expression of $A C A C A$ and FASN was greater in SAT than MAT, whereas expression of $S C D$ and $A D F P$ were greatest in SAT, intermediate in OAT, and lowest in MAT. However, the 2 visceral depots had greater expression of THRSP, $A C L Y, L P L, F A B P 4, G P A M$, and LPIN1 compared with SAT. The transcription factor $S R E B F 1$ was more highly expressed in MAT and SAT than in OAT. The expression of PNPLA2 was greater in visceral AT sites than in SAT, but other lipolysis-related genes were not differentially expressed among AT depots. Visceral AT depots had greater expression of $L E P, A D I P O Q$, and $S A A 3$ compared with SAT. Moreover, MAT had greater expression than SAT of proinflammatory cytokines (IL1B and IL6), IL6 receptor (IL6R), and chemokines (CCL2 and CCL5). However, TNF expression was greatest in SAT, lowest in OAT, and intermediate in MAT. Overall, results indicated that visceral AT might be more active in uptake of preformed long-chain fatty acids than SAT, whereas de novo fatty acid synthesis
\end{abstract}

\footnotetext{
Received July 25, 2013.

Accepted January 23, 2014

${ }^{1}$ Supported in part by National Institute of Food and Agriculture (NIFA; Washington, DC) project ILLU-538-914.

${ }^{2}$ Corresponding authors: drackley@illinois.edu and jloor@illinois. edu
}

could make a greater contribution to the intracellular pool of fatty acids in SAT than in visceral AT. The visceral AT compared with SAT seem to have a greater capacity for expression (and potentially for secretion) of proinflammatory cytokines; thus, excessive accumulation of visceral lipid due to a long-term overfeeding energy may be detrimental to liver function and overall health of dairy cows, particularly during the transition period.

Key words: visceral adipose tissue, gene expression, lipogenesis, inflammation

\section{INTRODUCTION}

Adipose tissue (AT) carries out important functions, including (1) lipogenesis to store surplus energy in the form of triacylglycerol (TAG); (2) lipolysis to release energy during periods of undernutrition in the form of NEFA and glycerol; and (3) secretion of a broad spectrum of cytokines, chemokines, and acute phase proteins, which links metabolism with the innate immune system. Adipose tissues from different sites of the body differ in metabolic activity, such as sensitivity to lipolytic stimuli (Giorgino et al., 2005), as well as secretory characteristics. For example, in humans, visceral AT (VAT) produces more proinflammatory cytokines than subcutaneous AT (SAT; Hamdy et al., 2006; Fontana et al., 2007). These differences result from anatomical location, relative proportions of various cell types (preadipocytes and mature adipocytes, resident macrophages), and the composition of extracellular matrix (Hassan et al., 2012). Obesity in nonruminants, particularly over-accumulation of VAT, is associated with chronic low-grade inflammation that is causally linked to many metabolic diseases (e.g., insulin resistance, diabetes, and cardiovascular disease) in rodent models and humans (Hotamisligil, 2006).

The use of BCS has been widely adopted as a practical way to monitor the degree of body fat storage and loss at different stages of lactation (Roche et al., 2009). Despite the reasonable accuracy for assessment of SAT stores, BCS may be a less effective predictor of internal and intramuscular fat storage (Wright and Russell, 1984). Reynolds et al. (2003) observed that 
VAT associated with the portal-drained viscera had a high degree of lipolytic activity during early lactation. A previous study from our laboratory demonstrated that proinflammatory cytokine mRNA expression in VAT and SAT responded differently to an in vitro LPS challenge (Mukesh et al., 2010), which may be due partly to the difference in immune cell infiltration in various AT sites that has been shown in obese mice (Weisberg et al., 2003) and human (Lim et al., 2013). Together, the limited data available indicate that VAT of dairy cattle may have a significant effect on wholebody metabolic responses, and particularly liver, due to the direct portal drainage.

Characterization of potential differences between VAT and SAT of dairy cows is important to improve understanding of lipid metabolism in each depot, which in the long-term might help decrease the incidence of lipid-related metabolic disorders. We used nonpregnant, nonlactating cows to replicate the effects of overfeeding in typical production systems without the confounding hormonal changes that occur around parturition. The present paper describes differences in expression of genes associated with adipogenesis, lipogenesis, lipolysis, and inflammation in 2 VAT (mesenteric and omental AT) and SAT. Results pertaining to the main effect of dietary energy intake on gene expression are presented in a companion paper (Ji et al., 2014).

\section{MATERIALS AND METHODS}

\section{Experimental Design, Animals, Diets, and Sampling}

All procedures were conducted under protocols approved by the University of Illinois Institutional Animal Care and Use Committee (Protocol No. 06194) and have been described in detail elsewhere (Drackley et al., 2014; Ji et al., 2014). Briefly, 18 nonpregnant, nonlactating Holstein cows $(\mathrm{BW}=656 \pm 29 \mathrm{~kg} ; \mathrm{BCS}$ $=3.04 \pm 0.25$; dried off at 60 to $130 \mathrm{~d}$ postpartum) were randomly assigned for $8 \mathrm{wk}$ to a moderate energy $\operatorname{diet}\left(\mathbf{H E} ; \mathrm{NE}_{\mathrm{L}}=1.62 \mathrm{Mcal} / \mathrm{kg}\right.$ of $\left.\mathrm{DM}\right)$ or a controlled energy diet $\left(\mathbf{L E} ; \mathrm{NE}_{\mathrm{L}}=1.35 \mathrm{Mcal} / \mathrm{kg}\right.$ of $\left.\mathrm{DM}\right)$ provided as TMR for ad libitum intake. Cows were blocked by initial BCS and previous experimental treatment (proprietary). The HE diet contained $73.8 \%$ forage from alfalfa silage, alfalfa hay, and corn silage, whereas the LE diet contained $81.7 \%$ forage, including $40.5 \%$ wheat straw (DM basis, see detailed ingredient composition and nutrient profile of diets in Drackley et al., 2014). At the end the 8-wk experiment, cows were euthanized at the College of Veterinary Medicine, University of Illinois, diagnostic facilities (Urbana). All visceral organs, omental AT (OAT), mesenteric AT (MAT), and perirenal AT were dissected and weighed. Subsamples of SAT from the left side of tail-head region, OAT, and MAT were harvested immediately following euthanasia and snap-frozen in liquid $\mathrm{N}_{2}$ until RNA extraction.

\section{RNA Extraction and Quality Assessment, Primer Design and Evaluation, Internal Control Gene Selection, and Quantitative PCR}

Complete details of these procedures are reported elsewhere (Ji et al., 2014). Briefly, tissue was weighed $(\sim 2.0 \mathrm{~g})$ and immediately placed into ice-cold TRIzol reagent ( $\sim 15 \mathrm{~mL}$; Invitrogen, Carlsbad, CA) with $1 \mu \mathrm{L}$ of linear acrylamide (Ambion Inc., Austin, TX). Total RNA was cleaned using RNeasy mini kit columns and genomic DNA was removed using the RNase-Free DNase Set (Qiagen, Valencia, CA). A portion of the RNA was diluted to $100 \mathrm{ng} / \mu \mathrm{L}$ with DNase- and RNasefree water before reverse transcription for synthesis of cDNA (Ji et al., 2014).

Primer Design and Evaluation. Genes tested in the current study are listed in Table 1 . Primers were designed and evaluated as previously described (Bionaz and Loor, 2008). The details of primer design, sequences, verification, and the description of genes measured are reported in a companion paper ( $\mathrm{Ji}$ et al., 2014). Briefly, primers were designed using Primer Express 3.0 (Applied Biosystems, Carlsbad, CA) with minimum amplicon size of 80 bp (amplicons of 100 to120 bp were used, if possible) and limited 3' $\mathrm{G}+\mathrm{C}$ percentage. Primer sets were intentionally designed to span exon-exon junctions.

Quantitative $\boldsymbol{P C R}$. The quantitative (q)PCR analyses were performed in a MicroAmp Optical 384Well Reaction Plate (Applied Biosystems). Within each well, $4 \mu \mathrm{L}$ of diluted cDNA combined with $6 \mu \mathrm{L}$ of mixture composed of $5 \mu \mathrm{L}$ of $1 \times$ SYBR Green master mix (Applied Biosystems), $0.4 \mu \mathrm{L}$ each of $10 \mu \mathrm{M}$ forward and reverse primers, and $0.2 \mu \mathrm{L}$ of DNase- and RNase-free water were added. Three replicates and a 6 -point standard curve plus the nontemplate control were run for each sample to test the relative expression level (User Bulletin \#2, Applied Biosystems). The qPCR was conducted using an ABI Prism $7900 \mathrm{HT}$ SDS instrument (Applied Biosystems) following conditions of 2 min at $50^{\circ} \mathrm{C}, 10 \mathrm{~min}$ at $95^{\circ} \mathrm{C}, 40$ cycles of $15 \mathrm{~s}$ at $95^{\circ} \mathrm{C}$ (denaturation), and 1 min at $60^{\circ} \mathrm{C}$ (annealing + extension). The presence of a single PCR product was verified by the dissociation protocol using incremental temperatures to $95^{\circ} \mathrm{C}$ for $15 \mathrm{~s}$, and then $65^{\circ} \mathrm{C}$ for $15 \mathrm{~s}$. The development of the standard curve was reported in the companion manuscript (Ji et al., 2014).

Selection and Evaluation of Internal Control Genes. Complete details of this procedure are reported in a companion paper (Ji et al., 2014). Briefly, 
Table 1. The gene symbol for full gene names recorded in National Center for Biotechnology Information (NCBI; http://www.ncbi.nlm.nih.gov/gene)

\begin{tabular}{|c|c|}
\hline Gene symbol & Gene name in NCBI \\
\hline$A B H D 5$ & Abhydrolase domain containing 5 \\
\hline$A C A C A$ & Acetyl-Co A carboxylase $\alpha$ \\
\hline$A C L Y$ & ATP citrate lyase \\
\hline$A C S L 1$ & Acyl-CoA synthetase long-chain family member 1 \\
\hline$A D R B 2$ & Adrenoceptor $\beta 2$, suface \\
\hline$A D F P / P L I N 2$ & Perilipin 2 \\
\hline$A D I P O Q$ & Adiponectin \\
\hline$C D 36$ & Thrombospondin receptor \\
\hline$C C L 2$ & Chemokine (C-C motif) ligand 2 \\
\hline$C C L 5$ & Chemokine (C-C motif) ligand 5 \\
\hline ELOVL6 & Elongation of long chain fatty acids family member 6 \\
\hline$F A S N$ & Fatty acid synthase \\
\hline $\mathrm{FABP}_{4}$ & Adipocyte fatty acid binding protein 4 \\
\hline$G P A M$ & Mitochondrial glycerol-3-phosphate acyltransferase \\
\hline HCAR $1 / G P R 81$ & Hydroxycarboxylic acid receptor 1 \\
\hline$I L 1 B$ & Interleukin-1 $\beta$ \\
\hline IL6 & Interleukin-6 \\
\hline$I L 6 R$ & Interleukin-6 receptor \\
\hline$L E P$ & Leptin \\
\hline LIPE & Hormone sensitive lipase \\
\hline LPIN1 & Lipin 1 \\
\hline$L P L$ & Lipoprotein lipase \\
\hline$M G L L$ & Monoglyceride lipase \\
\hline$M L X I P L / C h R E B P$ & MLX interacting protein-like \\
\hline$P D E 3 B$ & Phosphodiesterase 3B, cGMP-inhibited \\
\hline PLIN1 & Perilipin 1 \\
\hline PNPLA2 & Patatin-like phospholipase domain containing 2 \\
\hline$P P A R G$ & Peroxisome proliferator-activated receptor gamma \\
\hline SAA3 & Acute-phase serum amyloid A3 \\
\hline$S C D$ & Stearoyl-CoA desaturase \\
\hline$S R E B F 1$ & Sterol regulatory element binding transcription factor 1 \\
\hline THRSP & Thyroid hormone responsive SPOT 14 \\
\hline$T_{L} R_{4}$ & Toll-like receptor 4 \\
\hline$T N F$ & Tumor necrosis factor $\alpha$ \\
\hline
\end{tabular}

candidate internal control genes were selected following the procedures described previously by Mukesh et al. (2010). The 3 internal control genes chosen from 10 candidate genes were kelch-like ECH-associated protein 1 (KEAP1), tripartite motif-containing 41 (TRIM41), and mitochondrial ribosomal protein 63 (MRP63).

\section{Data Processing and Statistical Analysis}

The gene expression data reported by Ji et al. (2014) and those in this paper were analyzed as a 2 $\times 3$ factorial arrangement in a completely randomized design. The normalized $\mathrm{qPCR}$ data (relative mRNA expression) were subjected to tests of normality and homogeneity of variance using the UNIVARIATE and GLM procedures, respectively. The data were tested with ANOVA using the MIXED procedure of SAS (version 9.1; SAS Institute Inc., Cary, NC) using a model that included the fixed effect of diet, AT depot, and their interaction. Cow within treatment was random term. The data were expressed as least squares means with standard errors of the mean (Figures 1, 2, and 3). Significance was declared when $P<0.05$.

\section{RESULTS AND DISCUSSION}

Dietary energy intake exerted a consistent effect on gene expression in both VAT and SAT depots, which is described in a companion manuscript (Ji et al., 2014). Because interactions of adipose site and diet were not significant for any genes except $L P L$, differentially expressed genes among the 3 AT sites are discussed here. Differences reflected unique characteristics of each depot examined.

\section{Lipid Metabolism}

Lipogenesis. With exception of ELOVL6 ( $P=$ $0.17)$ and $C D 36(P=0.85)$, all genes associated with processes leading to TAG synthesis were differentially expressed $(P<0.05)$ among the 3 AT sites, with the largest differences always detected between MAT and SAT (Figure 1). Compared with the VAT, SAT exhibited greater expression of $A C A C A(P=0.001), F A S N$ $(P=0.0001)$, and $S C D(P=0.0001)$, which encode the major enzymes responsible for de novo FA synthesis and desaturation. The enzyme product of $A C L Y$, ATP 

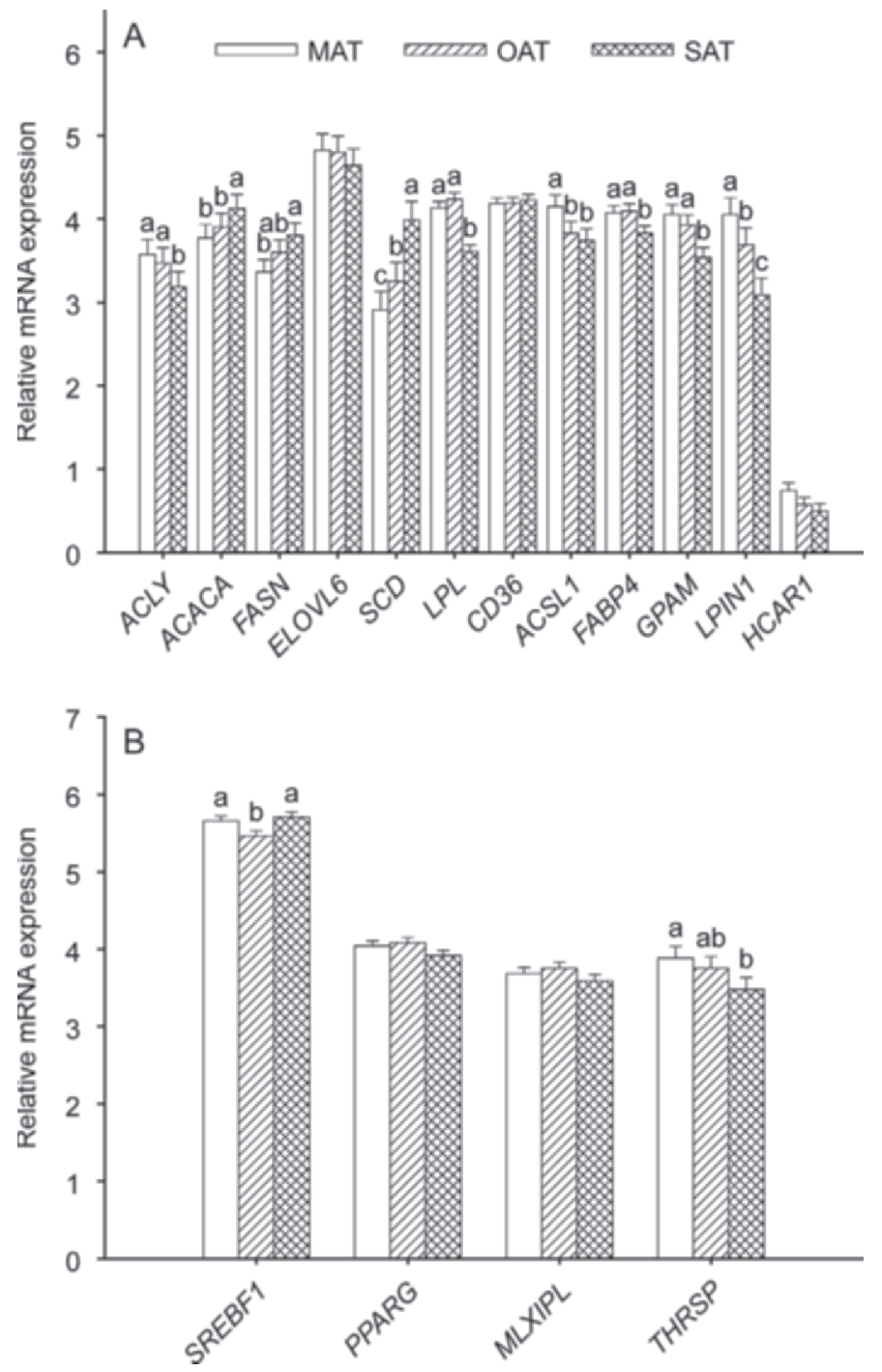

Figure 1. Main effect of adipose site on mRNA expression of genes involved in lipid metabolism (panel A) and transcription regulation (panel B). Within genes, different letters indicate differential expression among adipose sites $(P<0.05)$. The $\mathrm{x}$-axis indicates the official gene symbol from the National Center for Biotechnology Information (NCBI; http://www.ncbi.nlm.nih.gov/gene; see Table 1 for gene names); the $y$-axis indicates relative mRNA expression value from natural logarithmic transformed data. MAT $=$ mesenteric adipose tissue OAT $=$ omental adipose tissue; and SAT $=$ subcutaneous adipose tissue.

citrate lyase, converts glucose-derived citrate to cytosolic acetyl-CoA, which can then be used as substrate for de novo FA synthesis, despite the low preference for glucose as a lipogenic substrate in ruminant AT (Ingle et al., 1972). It is noteworthy that the expression of $A C L Y$ was greater in VAT than SAT $(P<0.05)$, which was opposite to the expression pattern of $A C A C A$ and $F A S N$. In contrast to FA synthesis, genes involved in long-chain FA (LCFA) uptake $(L P L)$, intracellular activation and transport (ACSL1 and FABP4), and TAG synthesis (GPAM and LPIN1) had greater expression in VAT, particularly in MAT $(P<0.05$; Figure 1$)$.

From a gene transcription standpoint, our results indicate that AT from different anatomic locations of dairy cattle varies in the relative enrichment of the pathways leading to TAG synthesis. Such depotspecific expression patterns also have been observed in beef cattle. For instance, Baldwin et al. (2007) observed that the general pattern of in vitro incorporation rate of acetate into FA per unit of cell volume from AT depots of beef steers was SAT > OAT > MAT. Eguinoa et al. (2003) reported that activities of glycerol-3-phosphate dehydrogenase and fatty acid synthase were greater in SAT than OAT or perirenal AT when adjusted for cell size. Because transcriptional regulation is the primary determinant of protein abundance of these enzymes in nonruminants (Foufelle and Ferre, 2002), the greater expression of $A C A C A$ and $F A S N$ in our study suggested that SAT has a potentially greater capacity for de novo FA synthesis than VAT.

The coordinated upregulation of $A C L Y$ with $A C A C A$ and FASN regardless of AT site in the energy-overfed (HE) group compared with the LE group (Ji et al., 2014) suggested the existence of co-regulation in response to greater dietary energy intake. However, the physiological reason for the difference in expression pattern between SAT and VAT of ACLY compared with the other FA biosynthetic genes ( $A C A C A$ and FASN) could not be discerned from our data.

Lipoprotein lipase is responsible for releasing LCFA from lipoprotein-associated TAG in blood, which then must be activated once inside cells by LCFA-CoA ligases before metabolism. Hocquette et al. (1998) reported that both $L P L$ mRNA expression and enzymatic activity in male calves were greater in internal AT depots (perirenal AT and OAT) than in SAT. Among all the LCFA ligase isoforms, ACSL1 was identified as the most highly expressed in mammary gland and SAT of dairy cows (Bionaz and Loor, 2008). Both GPAM and LPIN1 encode enzymes that participate in TAG synthesis (Takeuchi and Reue, 2009). The greater expression of these genes (LPL, ACSL1, GPAM, and LPIN1) in VAT, and especially in MAT, seems to highlight a greater potential for utilizing preformed LCFA for TAG synthesis in comparison with SAT.

Consistent with apparent differences in de novo FA synthesis, the expression of $S C D$ was greatest in SAT, lowest in MAT, and intermediate in OAT (Figure 1). This difference indicates that SAT may have a greater capacity for desaturating 16:0 and 18:0 to MUFA. Therefore, SAT appears to have not only a greater lipogenic capacity but also a greater ability to synthesize oleic acid (the primary FA found in SAT of dairy cows; Douglas et al., 2007) for esterification into 
TAG. Martin et al. (1999) observed that the peak of $S C D$ mRNA expression preceded a significant increase in lipogenesis and lipid filling in SAT of yearling steers. They concluded that the level of $S C D$ expression was indicative of the extent of terminal differentiation in bovine tail-head SAT.

The greater expression $(P=0.0002)$ of $F A B P 4$ in VAT compared with SAT deserves particular attention because this protein acts as a chaperone for intracellular LCFA, thus, facilitating their uptake but also their intracellular fate (e.g., esterification versus oxidation). Fatty acid binding protein 4 (FABP4) is a cytosolic lipid-binding protein highly expressed in adipocytes (Shen et al., 2001). The response for this gene in VAT was consistent with greater expression of $L P L, A C S L 1$, GPAM, and LPIN1, all of which would favor the channeling of LCFA toward TAG synthesis.

Lipolysis. A greater $(P=0.0003)$ expression of PNPLA2 was detected in both VAT sites compared with SAT (Figure 2). The expression of the lipolysisactivator protein $A B H D 5$ exhibited a pattern similar $(P=0.04)$ to that of $P N P L A 2$ specifically in MAT compared with SAT. However, the expression of PLIN2 (also known as $A D F P)$ was greatest $(P=0.0001)$ in SAT, intermediate in OAT, and lowest in MAT. Expression of ADRB2 $(P=0.23)$, PLIN1 $(P=0.63)$, LIPE $(P=0.25)$, and $M G L L(P=0.61)$ did not differ among AT sites.

During lipolysis, FABP4 helps shuttle intracellular LCFA toward the cellular membrane through its interaction with hormone-sensitive lipase (Furuhashi and Hotamisligil, 2008). Hence, FABP4 content appears to be proportional to the rates of FA metabolism (both mobilization and uptake or flux), which also is consistent with greater expression of PNPLA2 in VAT than in SAT. Targeted disruption of FABP 4 attenuates both basal and stimulated lipolysis (Scheja et al., 1999). Interestingly, FABP4 is abundantly expressed in activated macrophages that reside within AT stores and are functionally associated with many immune-mediated responses during metabolic disease states (e.g., insulin resistance; Makowski and Hotamisligil, 2004). Whether the greater expression of FABP\& in VAT in the current study was immune cell- or adipocyte-specific warrants further research.

Previous studies from our laboratory and others have demonstrated that hepatic TAG, hepatic total lipid content, and serum NEFA concentration during the dry period were not different in cows overfed energy compared with controls (Dann et al., 2006; Janovick et al., 2011). However, those studies demonstrated that cows overfed prepartum were predisposed to a more dramatic increase of hepatic lipid accumulation, circulating NEFA, and incidence of ketosis at the initiation of lactation. In cows overfed energy during the close-up dry period, greater expression of PNPLA2 (formerly $A T G L), A B D H 5$, and PLIN2 in SAT at $10 \mathrm{~d}$ prepartum persisted at $7 \mathrm{~d}$ postpartum, thus serving as a mechanism responsible at least in part for the increased NEFA mobilization postpartum (Ji et al., 2014). However, how VAT would respond to energy overfeeding before parturition in terms of lipolysis cannot be discerned from the present study.

Two classic studies by Reynolds et al. (2003, 2004) focusing on visceral organ metabolism of dairy cows during the transition period revealed that the net release of NEFA from portal-drained viscera increased nearly 3 times at 11 DIM compared with that at -7 DIM, and the total mass of VAT (MAT and OAT) was significantly reduced during the first 22 DIM compared with that in late gestation. In the present study, the greater expression of PNPLA2 in VAT compared with SAT underscored the potential for greater lipolytic activity per unit of VAT. Therefore, even though no diet $\times$ AT depot interaction was observed in our study (Ji et al., 2014), the $92 \%$ increase in MAT mass and the $76 \%$ increase in OAT mass in cows fed HE (Drackley et al., 2014) might have predisposed them to a much greater hepatic NEFA flux had they undergone a period of negative energy balance. It is possible, then, that if similar changes in AT mass are achieved in latepregnant transition cows because of energy overfeed-

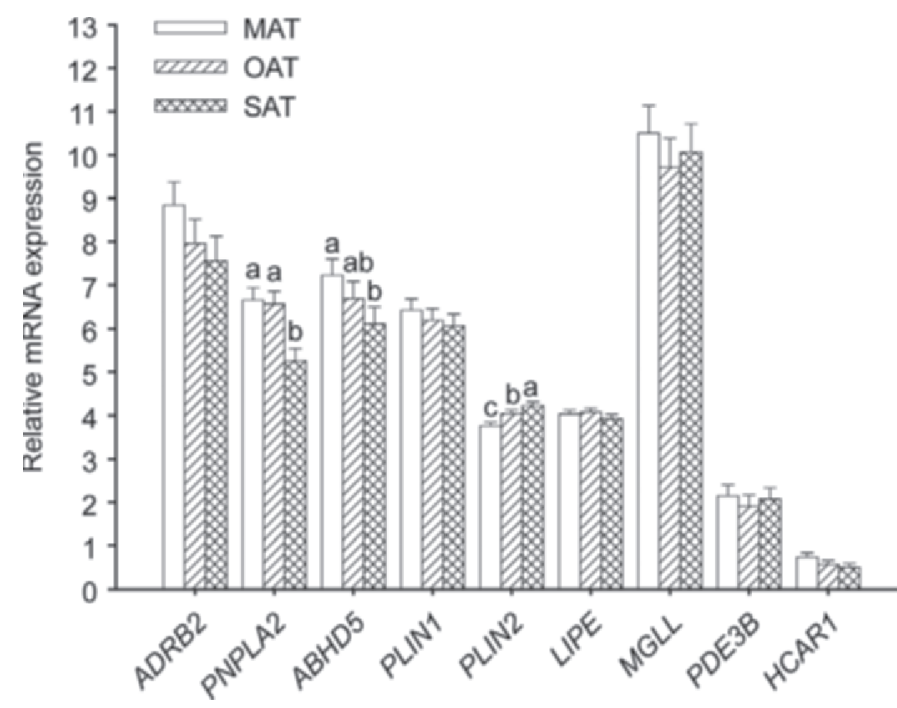

Figure 2. Main effect of adipose site on mRNA expression of lipolysis-related genes. Within genes, different letters indicate differential expression among adipose sites $(P<0.05)$. The $\mathrm{x}$-axis indicates the official gene symbol from the National Center for Biotechnology Information (NCBI; http://www.ncbi.nlm.nih.gov/gene; see Table 1 for gene names); the y-axis indicates relative mRNA expression value from natural logarithmic transformed data. MAT $=$ mesenteric adipose tissue; OAT $=$ omental adipose tissue; and $\mathrm{SAT}=$ subcutaneous adipose tissue. 
ing, they could be predisposed to developing metabolic disorders postpartum.

\section{Transcriptional Regulation of Lipogenesis}

Expression of $S R E B F 1$ was greater $(P=0.0001)$ in SAT and MAT than in OAT, whereas PPARG $(P=0.17)$ and $M L X I P L(P=0.16)$ were consistently expressed among AT depots (Figure 1). In rodent liver,s regulatory element binding transcription factor 1 (SREBF1) is a well-established control point of lipogenic gene expression (e.g., $F A S N, S C D$ ) in direct response to an increase in insulin and the ensuing signaling cascade leading to its maturation and activation (Horton et al., 2002). More recent work revealed that MLX interacting protein-like (MLXIPL), which is activated by the glycolytic intermediate ribulose-5-phosphate, could control approximately $50 \%$ of hepatic lipogenesis by regulating glycolytic and lipogenic gene expression (Iizuka and Horikawa, 2008) through binding to the carbohydrate response element in the promoter region of its target genes (Yamashita et al., 2001), including THRSP (Shih et al., 1995), ACACA, and FASN (Towle et al., 1997). Clearly, both of these transcription factors could overlap in terms of their gene targets in bovine AT, but it is likely that SREBF1 would be more biologically relevant because glucose is not a primary lipogenic substrate in bovine AT (Ingle et al., 1972).

It is well-established in rodents that peroxisome proliferator-activated receptor gamma $(\operatorname{PPAR} \gamma)$ and CCAAT/enhancer-binding protein alpha $(\mathrm{C} / \mathrm{EBP} \alpha)$ coordinate expression of adipogenic genes [e.g., FABP 4 and insulin-induced glucose transporter (SLC2A4, formerly known as GLUT4); Rosen and Spiegelman, 2000], and also SREBF1 and the adipokine adiponectin (Walkey and Spiegelman, 2008). Although the role of PPAR $\gamma$ in the control of adipogenesis is crucial, the fact that the heterodimer PPAR $\gamma:$ RXR can bind to thousands of response elements particularly abundant in the vicinity of genes involved in lipid and glucose metabolism in rodent adipocytes (Lefterova et al., 2008) suggests that it may also play a role in promoting lipogenesis; for example, partly through SREBF1 and directly through effects on specific target genes (e.g., $L P L, A C S L 1, F A B P 4, L P I N 1)$. From a practical standpoint, we have speculated that PPAR $\gamma$ activation via specific dietary LCFA (e.g., SFA and marine PUFA; Schmitt et al., 2011) could aid in manipulating AT deposition or insulin sensitivity during the transition from pregnancy into lactation.

The expression of THRSP differed $(P=0.0003)$ among AT depots, with greater values in VAT than SAT (Figure 3), which may underscore its importance in the ability of VAT (especially MAT) depots to ac- crete lipid. This depot-specific expression pattern might be induced by differing numbers of thyroid hormone receptors (TR) and the different ratios of TR isoforms among fat depots, which are required for transcriptional activation of THRSP (Cunningham et al., 1998). In humans, expression of TR $\alpha$ (an isomer of TR) and THRSP differed between SAT and OAT, and THRSP expression was significantly correlated with TR $\alpha$ mRNA level and with the TR $\alpha 1$ TR $\alpha 2$ ratio (Ortega et al., 2009). However, in contrast to our study, Ortega et al. (2009) found greater expression of these genes in SAT than in OAT, which may be associated with inherent species differences.

\section{Adipokines and Proinflammatory Cytokines}

In the current study, the expression of $A D I P O Q$ and $S A A 3$ was greater $(P=0.00001)$ in both VAT depots than in SAT, with no statistical difference between MAT and OAT (Figure 3). Leptin was differentially expressed $(P=0.0001)$ among the 3 depots, with the highest mRNA expression in OAT and the lowest in SAT. Mesenteric AT exhibited the highest expression of $\operatorname{IL1B}(P=0.0001)$ and $\operatorname{IL6R}(P=0.0001)$ among depots, and expression did not differ between OAT and SAT. The expression of chemokines (CCL2 and CCL5) was greater $(P=0.001)$ in MAT than in SAT. Although

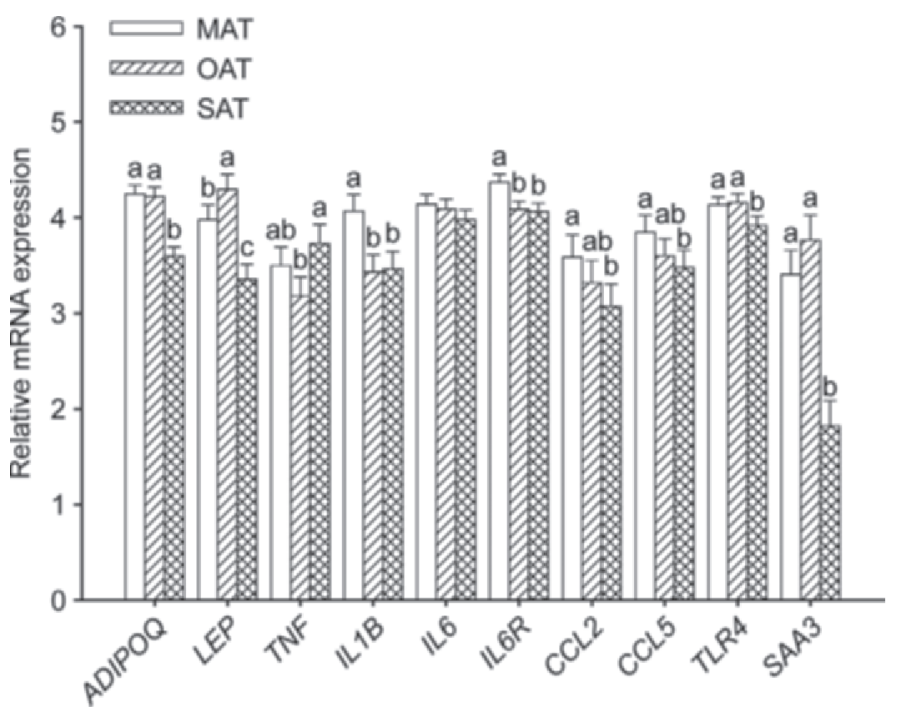

Figure 3. Main effect of adipose site on mRNA expression of adipokines. Within genes, different letters indicate differential expression among adipose sites $(P<0.05)$. The $\mathrm{x}$-axis indicates the official gene symbol from the National Center for Biotechnology Information (NCBI; http://www.ncbi.nlm.nih.gov/gene; see Table 1 for gene names); the $\mathrm{y}$-axis indicates relative mRNA expression value from natural logarithmic transformed data. MAT $=$ mesenteric adipose tissue; $\mathrm{OAT}=$ omental adipose tissue; and $\mathrm{SAT}=$ subcutaneous adipose tissue. 
expression of $I L 6$ did not differ $(P=0.26)$ among depots, $T N F \alpha$ expression was greater $(P=0.005)$ in SAT than in OAT.

In human and rodent models, visceral obesity is associated with chronic systemic low-grade inflammation (Fontana et al., 2007). Evidence also indicates that visceral obesity results in an increase in macrophage infiltration in VAT, which is causally linked with inflammation, liver disease, and insulin resistance (Hotamisligil, 2006). Our results seem to suggest that VAT, and especially MAT, of dairy cows might be more prone to produce most of the adipokines, proinflammatory cytokines, and chemokines. However, we could not determine if this was due to greater immune cell infiltration or to imprinted characteristics of VAT. Because the mass of MAT increased more than that of OAT as BCS increased (Drackley et al., 2014), this potential proinflammatory role of MAT in dairy cows could play a role in metabolic pathophysiology associated with overfeeding and excessive BCS.

Recently, Akter et al. (2012) utilized immunohistochemistry to determine potential differences in macrophage recruitment capacity between VAT and SAT of early-lactation Holstein cows. Only 7 out of 25 cows had positive staining for the macrophage marker CD68 in at least one AT depot, with numerically greater counts in VAT than in SAT. The authors ascribed these results to a greater metabolic rate and chemokine production of VAT. However, the authors acknowledged that the degree of fatness (BCS 3.0) might not have been enough to stimulate significant infiltration (Akter et al., 2012).

It is well established in nonruminants that adipocytes express several receptors for cytokines, including tumor necrosis factor- $\alpha$ and IL-1 $\beta$ (Fain et al., 2004). Therefore, an initially greater proinflammatory state due to more immune cells, greater cytokine secretory activity of VAT adipocytes, or simply greater VAT mass (Drackley et al., 2014) could exaggerate the inflammatory response of those depots through autocrine mechanisms. Upon hepatic delivery through the portal vein, these cytokines (e.g., IL1- $\beta$ and TNF $\alpha$ ) can then stimulate an acute phase response and alter hepatic function, thus contributing to a state of systemic inflammation, which would provide a feedback mechanism on AT depots. Further research is needed to confirm the immuno-endocrine activity of VAT and SAT as well as their link with peripheral tissues in periparturient dairy cows.

\section{CONCLUSIONS}

The greater mRNA expression of genes for lipolytic enzymes, proinflammatory cytokines, chemokines, and acute phase proteins in VAT along with the greater mass of VAT $(49.0$ and $25.7 \pm 2.76 \mathrm{~kg}$ for the sum of MAT and OAT in HE and LE cows, respectively; Drackley et al., 2014) suggests that overfeeding energy may predispose dairy cows to inflammation and potentially impaired liver function. Despite the limitations of deducing physiological changes by focusing on mRNA profiles, a logical implication of our results is that the effect of VAT metabolism on liver function and health may be much more prominent in cows overfed energy during the transition from late pregnancy into lactation. These findings are particularly important because of the poor association between BCS and VAT mass in the present work. Therefore, research to establish how nutritional management affects VAT metabolism and its immuno-endocrine functions during the periparturient period is warranted.

\section{REFERENCES}

Akter, S. H., S. Haussler, D. Germeroth, D. von Soosten, S. Danicke, K. H. Sudekum, and H. Sauerwein. 2012. Immunohistochemical characterization of phagocytic immune cell infiltration into different adipose tissue depots of dairy cows during early lactation. J. Dairy Sci. 95:3032-3044.

Baldwin, R. L., VI, K. R. McLeod, J. P. McNamara, T. H. Elsasser, and R. G. Baumann. 2007. Influence of abomasal carbohydrates on subcutaneous, omental, and mesenteric adipose lipogenic and lipolytic rates in growing beef steers. J. Anim. Sci. 85:2271-2282.

Bionaz, M., and J. J. Loor. 2008. Gene networks driving bovine milk fat synthesis during the lactation cycle. BMC Genomics 9:366.

Cunningham, B. A., J. T. Moncur, J. T. Huntington, and W. B. Kinlaw. 1998. "Spot 14" protein: A metabolic integrator in normal and neoplastic cells. Thyroid 8:815-825.

Dann, H. M., N. B. Litherland, J. P. Underwood, M. Bionaz, A. D'Angelo, J. W. McFadden, and J. K. Drackley. 2006. Diets during far-off and close-up dry periods affect periparturient metabolism and lactation in multiparous cows. J. Dairy Sci. 89:3563-3577.

Douglas, G. N., J. Rehage, A. D. Beaulieu, A. O. Bahaa, and J. K. Drackley. 2007. Prepartum nutrition alters fatty acid composition in plasma, adipose tissue, and liver lipids of periparturient dairy cows. J. Dairy Sci. 90:2941-2959.

Drackley, J. K., R. L. Wallace, D. Graugnard, J. Vasquez, B. F. Richards, and J. J. Loor. 2014. Visceral adipose tissue mass in nonlactating dairy cows fed diets differing in energy density. J. Dairy Sci. 97:3420-3430. 10.3168/jds.2014-8014.

Eguinoa, P., S. Brocklehurst, A. Arana, J. A. Mendizabal, R. G. Vernon, and A. Purroy. 2003. Lipogenic enzyme activities in different adipose depots of Pirenaican and Holstein bulls and heifers taking into account adipocyte size. J. Anim. Sci. 81:432-440.

Fain, J. N., A. K. Madan, M. L. Hiler, P. Cheema, and S. W. Bahouth. 2004. Comparison of the release of adipokines by adipose tissue, adipose tissue matrix, and adipocytes from visceral and subcutaneous abdominal adipose tissues of obese humans. Endocrinology 145:2273-2282.

Fontana, L., J. C. Eagon, M. E. Trujillo, P. E. Scherer, and S. Klein. 2007. Visceral fat adipokine secretion is associated with systemic inflammation in obese humans. Diabetes 56:1010-1013.

Foufelle, F., and P. Ferre. 2002. New perspectives in the regulation of hepatic glycolytic and lipogenic genes by insulin and glucose: A role for the transcription factor sterol regulatory element binding protein-1c. Biochem. J. 366:377-391.

Furuhashi, M., and G. S. Hotamisligil. 2008. Fatty acid-binding proteins: Role in metabolic diseases and potential as drug targets. Nat. Rev. Drug Discov. 7:489-503.

Giorgino, F., L. Laviola, and J. W. Eriksson. 2005. Regional differences of insulin action in adipose tissue: Insights from in vivo and in vitro studies. Acta Physiol. Scand. 183:13-30. 
Hamdy, O., S. Porramatikul, and E. Al-Ozairi. 2006. Metabolic obesity: The paradox between visceral and subcutaneous fat. Curr. Diabetes Rev. 2:367-373.

Hassan, M., N. Latif, and M. Yacoub. 2012. Adipose tissue: Friend or foe? Nat. Rev. Cardiol. 9:689-702.

Hocquette, J. F., B. Graulet, and T. Olivecrona. 1998. Lipoprotein lipase activity and mRNA levels in bovine tissues. Comp. Biochem. Physiol. B Biochem. Mol. Biol. 121:201-212.

Horton, J. D., J. L. Goldstein, and M. S. Brown. 2002. SREBPs: Activators of the complete of cholesterol and fatty acid synthesis in the liver. J. Clin. Invest. 109:1125-1131.

Hotamisligil, G. S. 2006. Inflammation and metabolic disorders. Nature 444:860-867.

Iizuka, K., and Y. Horikawa. 2008. ChREBP: A glucose-activated transcription factor involved in the development of metabolic syndrome. Endocr. J. 55:617-624.

Ingle, D. L., D. E. Bauman, and U. S. Garrigus. 1972. Lipogenesis in the ruminant: In vitro study of tissue sites, carbon source and reducing equivalent generation for fatty acid synthesis. J. Nutr. 102:609-616.

Janovick, N. A., Y. R. Boisclair, and J. K. Drackley. 2011. Prepartum dietary energy intake affects metabolism and health during the periparturient period in primiparous and multiparous Holstein cows. J. Dairy Sci. 94:1385-1400.

Ji, P., J. K. Drackley, M. J. Khan, and J. J. Loor. 2014. Overfeeding energy upregulates peroxisome proliferator-activated receptor (PPAR) $\gamma$-controlled adipogenic and lypolytic gene networks but does not affect proinflammatory markers in visceral and subcutaneous adipose depots of Holstein cows. J. Dairy Sci. 97:3431-3440. 10.3168/jds.2013-7295.

Lefterova, M. I., Y. Zhang, D. J. Steger, M. Schupp, J. Schug, A Cristancho, D. Feng, D. Zhuo, C. J. Stoeckert Jr., X. S. Liu, and M. A. Lazar. 2008. PPARgamma and C/EBP factors orchestrate adipocyte biology via adjacent binding on a genome-wide scale. Genes Dev. 22:2941-2952.

Lim, J., A. Iyer, L. Liu, J. Y. Suen, R. J. Lohman, V. Seow, M K. Yau, L. Brown, and D. P. Fairlie. 2013. Diet-induced obesity, adipose inflammation, and metabolic dysfunction correlating with PAR2 expression are attenuated by PAR2 antagonism. FASEB J. 27:4757-4767.

Makowski, L., and G. S. Hotamisligil. 2004. Fatty acid binding proteins - The evolutionary crossroads of inflammatory and metabolic responses. J. Nutr. 134:2464S-2468S

Martin, G. S., D. K. Lunt, K. G. Britain, and S. B. Smith. 1999. Postnatal development of stearoyl coenzyme A desaturase gene expression and adiposity in bovine subcutaneous adipose tissue. J. Anim. Sci. 77:630-636.

Mukesh, M., M. Bionaz, D. E. Graugnard, J. K. Drackley, and J. J. Loor. 2010. Adipose tissue depots of Holstein cows are immune responsive: Inflammatory gene expression in vitro. Domest. Anim. Endocrinol. 38:168-178.

Ortega, F. J., J. M. Moreno-Navarrete, V. Ribas, E. Esteve, J. I Rodriguez-Hermosa, B. Ruiz, B. Peral, W. Ricart, A. Zorzano, and
J. M. Fernandez-Real. 2009. Subcutaneous fat shows higher thyroid hormone receptor-alpha1 gene expression than omental fat. Obesity (Silver Spring) 17:2134-2141.

Reynolds, C. K., P. C. Aikman, B. Lupoli, D. J. Humphries, and D. E. Beever. 2003. Splanchnic metabolism of dairy cows during the transition from late gestation through early lactation. J. Dairy Sci. 86:1201-1217.

Reynolds, C. K., B. Durst, B. Lupoli, D. J. Humphries, and D. E. Beever. 2004. Visceral tissue mass and rumen volume in dairy cows during the transition from late gestation to early lactation. J. Dairy Sci. 87:961-971.

Roche, J. R., N. C. Friggens, J. K. Kay, M. W. Fisher, K. J. Stafford and D. P. Berry. 2009. Invited review: Body condition score and its association with dairy cow productivity, health, and welfare. J. Dairy Sci. 92:5769-5801.

Rosen, E. D., and B. M. Spiegelman. 2000. Molecular regulation of adipogenesis. Annu. Rev. Cell Dev. Biol. 16:145-171.

Scheja, L., L. Makowski, K. T. Uysal, S. M. Wiesbrock, D. R. Shimshek, D. S. Meyers, M. Morgan, R. A. Parker, and G. S. Hotamisligil. 1999. Altered insulin secretion associated with reduced lipolytic efficiency in aP2-/- mice. Diabetes 48:1987-1994.

Schmitt, E., M. A. Ballou, M. N. Correa, E. J. DePeters, J. K. Drackley, and J. J. Loor. 2011. Dietary lipid during the transition period to manipulate subcutaneous adipose tissue peroxisome proliferator-activated receptor-gamma co-regulator and target gene expression. J. Dairy Sci. 94:5913-5925.

Shen, W. J., Y. Liang, R. Hong, S. Patel, V. Natu, K. Sridhar, A. Jenkins, D. A. Bernlohr, and F. B. Kraemer. 2001. Characterization of the functional interaction of adipocyte lipid-binding protein with hormone-sensitive lipase. J. Biol. Chem. 276:49443-49448.

Shih, H. M., Z. Liu, and H. C. Towle. 1995. Two CACGTG motifs with proper spacing dictate the carbohydrate regulation of hepatic gene transcription. J. Biol. Chem. 270:21991-21997.

Takeuchi, K., and K. Reue. 2009. Biochemistry, physiology, and genetics of GPAT, AGPAT, and lipin enzymes in triglyceride synthesis. Am. J. Physiol. Endocrinol. Metab. 296:E1195-E1209.

Towle, H. C., E. N. Kaytor, and H. M. Shih. 1997. Regulation of the expression of lipogenic enzyme genes by carbohydrate. Annu. Rev. Nutr. 17:405-433

Walkey, C. J., and B. M. Spiegelman. 2008. A functional peroxisome proliferator-activated receptor-gamma ligand-binding domain is not required for adipogenesis. J. Biol. Chem. 283:24290-24294

Weisberg, S. P., D. McCann, M. Desai, M. Rosenbaum, R. L. Leibel, and A. W. Ferrante. 2003. Obesity is associated with macrophage accumulation in adipose tissue. J. Clin. Invest. 112:1796-1808.

Wright, I. A., and A. J. F. Russell. 1984. Partition of fat, body composition and body condition score in mature cows. Anim. Prod. $38: 23-32$.

Yamashita, H., M. Takenoshita, M. Sakurai, R. K. Bruick, W. J. Henzel, W. Shillinglaw, D. Arnot, and K. Uyeda. 2001. A glucoseresponsive transcription factor that regulates carbohydrate metabolism in the liver. Proc. Natl. Acad. Sci. USA 98:9116-9121. 